\title{
Near Discharge Cathode Assembly Plasma Potential Measurements in a 30-cm NSTAR- type Ion Engine amidst Beam Extraction
}

\author{
Daniel A. Herman ${ }^{\dagger}$ and Alec D. Gallimore \\ Plasmadynamics and Electric Propulsion Laboratory \\ University of Michigan, Ann Arbor, MI 48109 USA
}

\begin{abstract}
Floating emissive probe plasma potential data are presented over a two-dimensional array of locations in the near Discharge Cathode Assembly (DCA) region of a 30-cm diameter ring-cusp ion thruster. Discharge plasma data are presented with beam extraction at throttling conditions comparable to the NASA TH Levels 8, 12, and 15. The operating conditions of the Extended Life Test (ELT) of the Deep Space One (DS1) flight spare ion engine, where anomalous discharge keeper erosion occurred, were TH 8 and TH 15; consequently, they are of specific interest in investigating discharge keeper erosion phenomena. ${ }^{5,6}$ The data do not validate the presence of a potential hill plasma structure downstream of the DCA, which has been proposed as a possible erosion mechanism. ${ }^{9,10}$ The data are comparable in magnitude to data taken by other researchers in ring-cusp electron-bombardment ion thrusters. ${ }^{23,24}$ The plasma potential structures are insensitive to thruster throttling level with a minimum as low as $14 \mathrm{~V}$ measured at the DCA exit plane increasing gradually in the axial direction. Shorting of the discharge keeper to discharge cathode common, at roughly NASA TH 8, did not have a significant effect on the near DCA plasma structure. A sharp increase in plasma potential to the bulk discharge value of $26-28$ volts, radially past the discharge keeper edge, was observed. Plasma potential measurements indicate a low-potential plume structure emanating from the discharge cathode that may be attributed to a free-standing plasma double layer. ${ }^{25}$
\end{abstract}

\section{Nomenclature}

$B \quad=$ magnetic field magnitude, Gauss

$d \quad=$ emitting filament wire diameter, $\mathrm{mm}$

$J_{a} \quad=$ acceleration grid current, $\mathrm{mA}$

$J_{b} \quad=$ beam current, $\mathrm{A}$

$J_{d c} \quad=$ discharge current, $\mathrm{A}$

$J_{n k} \quad=$ neutralizer keeper current, A

$P_{b} \quad=$ base pressure (air), Torr

$P_{i} \quad=$ indicated pressure (xenon), Torr

$\begin{array}{ll}P_{c} & =\text { corrected pressure (xenon), Torr } \\ T_{e V} & =\text { electron temperature, } \mathrm{eV} \\ V_{a} & =\text { acceleration grid voltage, } \mathrm{V} \\ V_{c k-c c} & =\text { keeper to cathode common voltage, } \mathrm{V} \\ V_{d c} & =\text { discharge voltage, } \mathrm{V} \\ V_{n k} & =\text { neutralizer keeper voltage, } \mathrm{V} \\ V_{s} & =\text { screen grid voltage, } \mathrm{V} \\ \phi_{p} \text { or } \mathrm{V}_{\mathrm{p}} & =\text { local plasma potential, } \mathrm{V}\end{array}$

* Color copies available at http://www.engin.umich.edu/dept/aero/spacelab/publications/conf_pub.html.

${ }^{\dagger}$ Graduate Student, Aerospace Engineering, hermo@engin.umich.edu, 1919 Green Rd Room B107, Member AIAA.

${ }^{\ddagger}$ Professor and Laboratory Director, Aerospace Engineering, Alec.gallimore@umich.edu, Associate Fellow AIAA. 


\section{Introduction}

I ON thrusters are high-efficiency, high-specific impulse $\left(\mathrm{I}_{\mathrm{sp}}\right)$ propulsion systems that are being proposed as the primary propulsion source for a variety of missions. In some cases ion thruster technology has enabled new missions that had not been feasible using liquid propellant rocket technology. NASA's Dawn mission, propelled by three 30-cm ion thrusters, will study two minor planets, Ceres and Vesta, which reside in the vast asteroid belt between Mars and Jupiter. ${ }^{\S}$ The NASA Solar Electric Propulsion Technology Applications Readiness (NSTAR) 30$\mathrm{cm}$ ion thruster was the first ion engine to be used for primary spacecraft propulsion, validating ion thruster technology, and demonstrating operation for over three times its intended lifetime. ${ }^{* *}$ Nevertheless, efforts to increase engine lifetime continue.

A potential failure mechanism for an ion engine is erosion of the discharge cathode. ${ }^{1}$ Investigation of the discharge cathode erosion led to evidence that direct ion impingement was the cause. A cathode keeper was added, as an engineering solution to mitigate cathode erosion on NSTAR. ${ }^{2}$ Adding the keeper reduced the cathode erosion rate to acceptable levels and, until recently, was thought to have solved the Discharge Cathode Assembly (DCA) erosion issue. An Extended Life Test (ELT) of the NSTAR Deep Space One (DS1) flight spare thruster, conducted at the Jet Propulsion Laboratory (JPL), revealed extensive keeper erosion that has yet to be fully exp lained..$^{3-6}$ Although the engine continued to operate until it was voluntarily shut down after 30,352 hours of operation (over $235 \mathrm{~kg}$ of xenon processed) $)^{6}$, there exists a clear need to understand the cause of DCA erosion, how engine operating conditions affect DCA erosion, and how to reduce DCA erosion thereby extending engine lifetime. A better understanding of discharge cathode erosion mechanisms may be even more important for the next-generation of ion engines associated with NASA's Project Prometheus that require lifetimes ranging from 44,000 to 88,000 hours. ${ }^{7,8}$

Laser Induced Fluorescence (LIF) measurements by Williams have suggested the existence of a potential hill downstream of the DCA as a possible cause of DCA erosion. ${ }^{9-11}$ In this scenario, the potential hill is responsible for accelerating a portion of the ions away from the hill towards the DCA. Mapping the internal plasma structure of the 30-cm ion engine downstream of the DCA is essential to understanding the cause of DCA erosion and could validate or rule out the potential hill theory. The purpose of this experiment is to take high-spatial resolution plasma potential measurements in the near DCA region of the $30-\mathrm{cm}$ ion engine.

\section{FMT2 30-cm Ion Thruster}

\section{A. Background}

The Functional Model Thruster (FMT) preceded the NSTAR Engineering Model Thruster (EMT) and the NSTAR Flight Thruster. The principal difference in the construction of the FMT from the EMT is the anode material. The FMT anode is aluminum while the EMT anode is spun aluminum and titanium. The second of two FMTs, FMT2, was modified at the NASA Glenn Research Center (GRC) by Williams to allow optical access to the discharge chamber for LIF measurements. ${ }^{9}$ Six slots were cut into FMT2: three slots in the anode wall and three slots in the plasma shield. Photographs of the FMT2 ion engine and the LIF modifications can be seen in Figure 1.

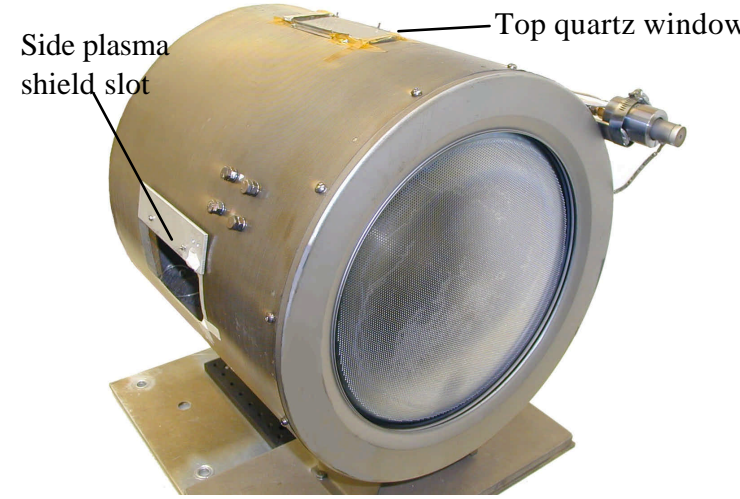

a)

Figure 1. The FMT2 ion engine illustrating the locations of the top and side quarts window mount a), as well as a close-up view of the FMT2 side LIF slots and quartz window mounts with quartz removed b).

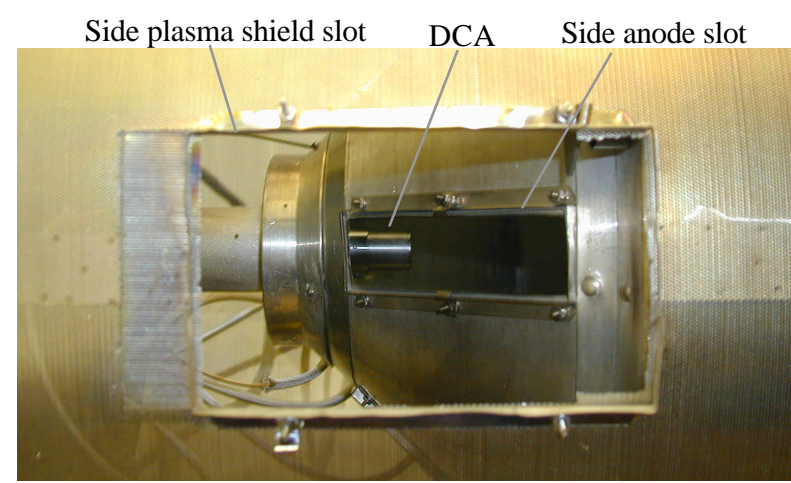

b)

$\S$ http://solarsystem.nasa.gov/missions/astmissns/ast-dawn.html

http://nmp.jpl.nasa.gov/ds1/gen/mission.html 
The magnetic field, DCA, and geometry of the discharge chamber are identical to those of the EMT1. ${ }^{9}$ For a more complete comparison between FMT2 and EMT1 see Reference 9. The FMT2 thruster has been operated over the entire NSTAR power throttling range at GRC and at the Plasmadynamics and Electric Propulsion Laboratory (PEPL) illustrating comparable performance to the EMTs and flight thrusters. Williams has shown that these modifications have not altered the discharge chamber magnetic field, the ion production efficiency, or the overall thruster performance. ${ }^{9}$

\section{B. Discharge Plasma Containment Mechanism}

The side anode quartz window is replaced by a discharge plasma containment mechanism allowing electrostatic probe access inside the anode. The design, shown in Figure 2, consists of a series of overlapping 38-guage slotted stainless steel sheets.

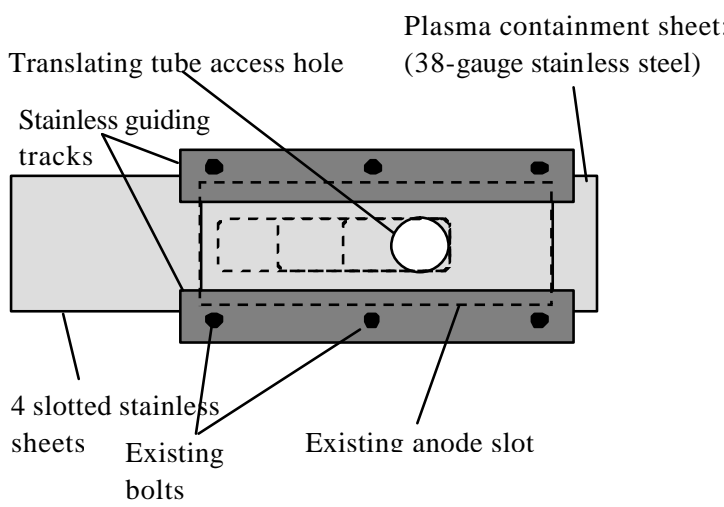

a)

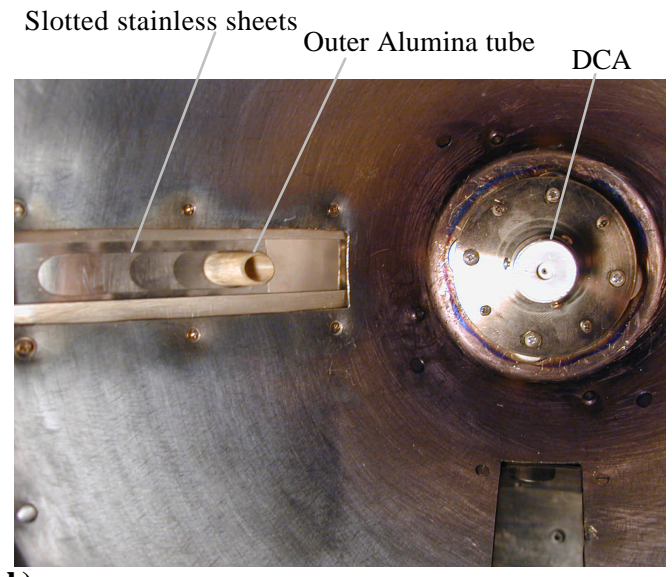

b)

Figure 2. Schematic of the discharge plasma containment hardware covering the anode side slot shown in a), along with a photograph taken inside the FMT2 discharge chamber prior to engine testing showing the interior of the discharge plasma containment mechanism in b).

Repeatable axial movement of the probe is permissible. Discharge plasma containment is maintained and visually monitored during thruster operation via an adjacent vacuum-rated camera. Gap formation, while extracting a beam, leads to a surge of discharge plasma towards the hole as the high-voltage plasma escapes to ground. Repeated recycles of the engine ensue. The vacuum-rated camera allows confirmation that no gap formation has occurred throughout the test and that any engine recycles are not a result of gap formation.

The ability to retract and ext end the translating alumina tube at various axial locations minimizes protrusion of material into the discharge chamber. The alumina tube extends approximately $1 \mathrm{~cm}$ inside of the discharge chamber wall at all axial locations. The alumina tube is mounted onto a New England Affiliated Technologies (NEAT) RMS-800 single axis ball screw table controlled via computer. The table has a lead screw accuracy of $80 \mu \mathrm{m}$ and a range of motion of $20 \mathrm{~cm}$. Figure 3 illustrates the emissive probe experimental setup. For more information on the discharge plasma containment mechanism, see Reference 12.

To minimize the likelihood of probe contamination and perturbing the discharge plasma, the probe is recessed in the low-density interior of the alumina tube when not in use. A rectangular aluminum plate covers the side plasma shield slot eliminating the line of sight of background particles (i.e., electrons) to the high potential anode.

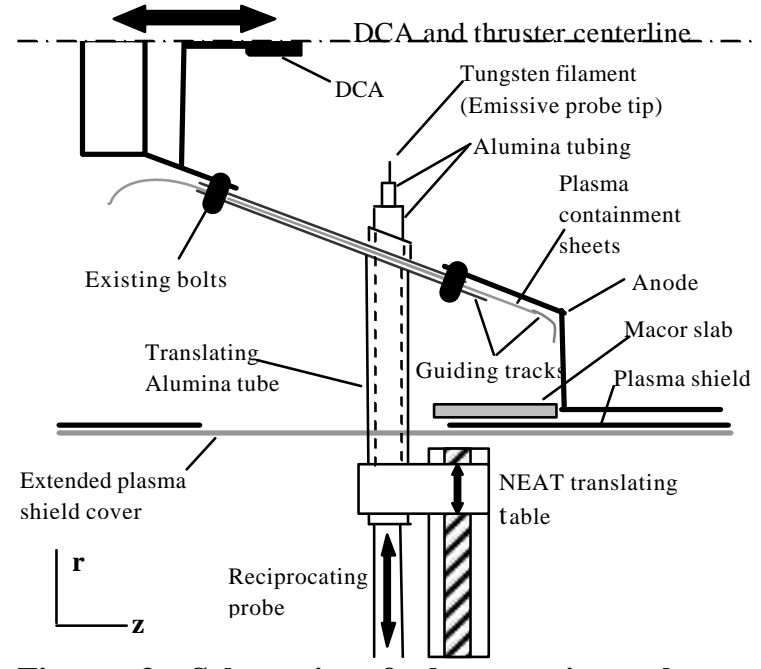

Figure 3. Schematic of the experimental setup focusing on the discharge plasma containment and thruster orientation. 


\section{Apparatus and Procedure}

\section{A. Vacuum Facility}

All experiments are performed in the $6 \mathrm{~m}$ by $9 \mathrm{~m}$ Large Vacuum Test Facility (LVTF) at PEPL. Four of the seven CVI Model TM-1200 Re-Entrant Cryopumps are used for these experiments, which provide a combined pumping speed of 140,000 1/s on xenon with a base pressure of $\sim 3 \times 10^{-7}$ Torr. Chamber pressure is recorded using a hot-cathode ionization gauge mounted directly on the chamber wall. A complete neutral pressure map of the LVTF has shown that the wall-mounted ion gauge pressure is representative of the chamber background pressure near the thruster in this facility. ${ }^{13}$ Pressure measurements are corrected for xenon using the known base pressure on air and a correction factor of 2.87 for xenon according to, ${ }^{13-15}$

$$
P_{c}=\frac{P_{i}-P_{b}}{2.87}+P_{b} .
$$

A dedicated propellant feed system, consisting of three Edwards mass flow controllers, provided by NASA GRC, controls the xenon flow rate to the thruster. The flow rates are periodically calibrated using a known volume technique.

A $2 \mathrm{~m}$ by $2.5 \mathrm{~m}$ louvered graphite panel beam dump is positioned approximately $4 \mathrm{~m}$ downstream of the FMT2 thruster to reduce back sputtering. The thruster is operated at PEPL using a modified Station-Keeping Ion Thruster Package (SKIT-Pac) power processing and control rack provided by NASA GRC. Unless specified otherwise, the discharge cathode keeper is electrically connected to the anode by a $10 \mathrm{k}$ ? resistor throughout testing.

\section{B. High-speed Axial Reciprocating Probe (HARP)}

A linear motor assembly provides highly accurate direct linear motion of the probe with minimal residence times in the discharge cathode plume. The HARP system is a three-phase brushless dc servo motor consisting of a linear "U"-shaped magnet track and a "T"-shaped coil moving on a set of linear tracks. The linear encoder provides positioning resolution to $5 \mu \mathrm{m} .{ }^{16}$ A Pacific Scientific SC950 digital, brushless servo drive controls the motor. The entire table is enclosed in a stainless steel shroud with a graphite outer skin. Residence times of the probe inside the discharge chamber are kept under one second to minimize probe heating and discharge plasma perturbation. The residence time of the probe downstream of the DCA, inside the high-density discharge cathode plume, is typically 100 milliseconds. The short residence times minimize the discharge plasma perturbation during probe insertion, which is monitored by the discharge current perturbation during probe insertion. The maximum perturbation recorded during probe insertion was $5-10 \%$ of the discharge current nominal value. Additional information on the HARP system can be found in References 16 and 17.

\section{Axial Movement}

The FMT2 is mounted on an ATS62150 Aerotech single-axis translational stage. The Aerotech axis controls the engine axial location with respect to the probe to an absolute position accuracy of $0.15 \mathrm{~mm}$. An axial step size of 1.5 $\mathrm{mm}$ is used to give adequate resolution of the possible potential hill structure that has been proposed to exist within a few centimeters of the discharge keeper exit plane. ${ }^{9}$ The emissive probe is radially positioned inside the discharge chamber using the HARP. Both the HARP system and the Aerotech table are mounted on a common structure whose foundation is the vacuum facility wall. This setup minimizes alignment shifts occurring during vacuum chamber evacuation. When actuated, the probe extends to the thruster centerline then returns to the starting location recessed inside the translating alumina tube. The RMS-800 NEAT table retracts and extends the translating alumina tube as the axial location changes. The full 2-D data collection domain is illustrated in Figure 4. 

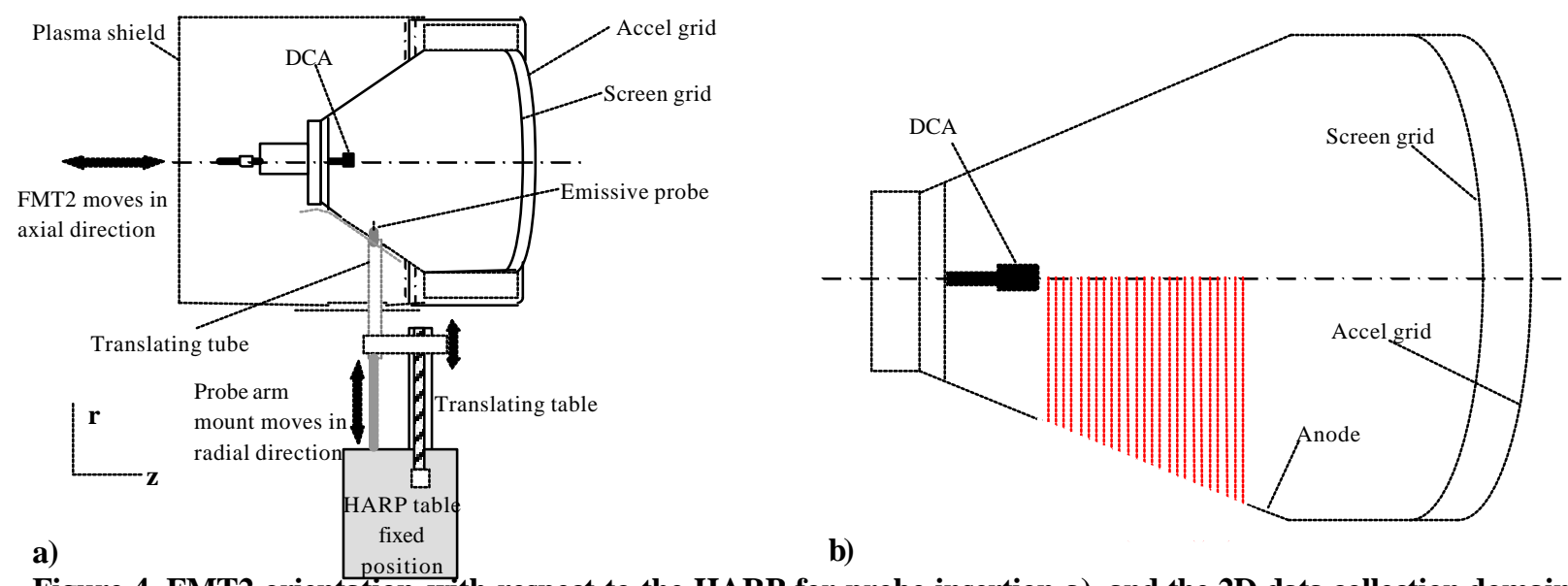

Figure 4. FMT2 orientation with respect to the HARP for probe insertion a), and the 2D data collection domain starting at an axial location of $1.5 \mathrm{~mm}$ from the DCA and increasing in $1.5 \mathrm{~mm}$ increments $\mathrm{b}$ ).

\section{FMT2 Thruster Operation}

For this near DCA investigation, the primary thruster operating parameters of interest are the discharge current and voltage, the screen voltage, and the beam current. The procedure for operating the FMT 2 with beam extraction is to throttle up the discharge current and screen voltage to match the desired NASA TH Level discharge current. The main and discharge flow rates are adjusted until both the discharge cathode voltage and beam current match the corresponding NASA throttling table values. The engine is operated without neutralizer emission current for this experiment due to difficulty igniting the neutralizer cathode. For this experiment, an equivalent mass flow rate from previous FMT2 testing with the neutralizer ignited is set for the neutralizer and the neutralizer common lead is grounded to facility ground. The data taken with beam extraction are referred to as Thruster Operating Conditions (TOC Levels). Table 1 details the complete listing of the thruster telemetry for the operating condition investigated in this experiment.

Table 1. FMT2 Thruster Operating Conditions (TOC) with beam extraction corresponding to the NASA Throttling Level (TH) indicated in grey for reference.

\begin{tabular}{|c|c|c|c|c|c|c|c|c|c|c|c|c|c|}
\hline & $V_{d c}$ & $J_{d c}$ & $V_{\text {ck-cc }}$ & $V_{s}$ & $J_{b}$ & $\mathrm{~V}_{\mathrm{a}}$ & $\mathrm{J}_{\mathrm{a}}$ & $V_{n k}$ & $J_{n k}$ & $\begin{array}{l}\text { Main } \\
\text { flow }\end{array}$ & $\begin{array}{l}\text { Disch } \\
\text { Cath. } \\
\text { flow }\end{array}$ & $\begin{array}{l}\text { Neut } \\
\text { Cath. } \\
\text { flow }\end{array}$ & $\mathrm{Pc}_{\mathrm{c}}$ \\
\hline Level & $\mathrm{V}$ & A & $\mathrm{V}$ & $\mathrm{V}$ & A & $\mathrm{V}$ & $\mathrm{mA}$ & $\mathrm{V}$ & $A$ & $\mathrm{sccm}$ & $\mathrm{sccm}$ & $\mathrm{sccm}$ & Torr \\
\hline 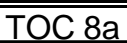 & 25.20 & $\overline{8.24}$ & $\begin{array}{l}7.70 \\
\end{array}$ & 11100 & 1.1 .10 & -180.0 & 5.46 & $\overline{-}$ & ב- & $\begin{array}{l}17.0 \\
\end{array}$ & 4 & 4.49 & 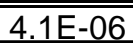 \\
\hline TOC 8 & 25.20 & 8.24 & 6.84 & 1100 & 1.10 & -180.0 & 5.15 & - & - & 17.1 & 4.54 & 4.49 & $4.1 \mathrm{E}-06$ \\
\hline $\begin{array}{c}\text { TOC } 8 \\
\text { short }\end{array}$ & 25.15 & 8.24 & 0 & 1100 & 1.10 & -180.0 & 5.09 & & & 16.9 & 4.64 & 4.49 & $4.2 \mathrm{E}-06$ \\
\hline TH 8 & 25.10 & 8.24 & - & 1100 & 1.10 & -180.0 & 3.139 & 15.32 & 1.50 & 14.41 & 2.47 & 2.40 & - \\
\hline TOC 12 & 25.40 & 10.87 & 5.86 & 1100 & 1.49 & -180.0 & 6.94 & - & - & 21.6 & 3.52 & 4.49 & $4.4 \mathrm{E}-06$ \\
\hline $\mathrm{TH} 12$ & 25.40 & 10.87 & - & 1100 & 1.49 & -180.0 & 4.704 & 14.52 & 1.50 & 19.86 & 2.89 & 2.81 & - \\
\hline TOC 15 & 25.15 & 13.13 & 5.47 & 1100 & 1.76 & -180.1 & 8.46 & - & - & 24.8 & 3.13 & 4.49 & $4.6 \mathrm{E}-06$ \\
\hline TH 15 & 25.14 & 13.13 & - & 1100 & 1.76 & -180.0 & 5.993 & 14.02 & 1.50 & 23.43 & 3.70 & 3.60 & \\
\hline
\end{tabular}

\section{Emissive Probe}

\section{A. Emissive Probe Theory}

The floating emissive probe operates under a simple principle yielding direct measurement of the local plasma potential without the need for a bias voltage sweep or extensive data analysis. The theory of the floating emissive probe is well established. ${ }^{17-19}$ Current is applied through a filament that is inserted into the plasma at the point of interest. As the filament heats up, electrons are thermionically emitted from the filament. When heated sufficiently, the emitted electrons essentially neutralize the sheath around the probe tip allowing the probe (and probe circuitry) to float at the local plasma potential. 


\section{B. Emissive Probe Filament}

The filament of the emissive probe was selected as the smallest available diameter tungsten wire that allows manageable construction of the emissive probe and has adequate survivability under the high accelerating forces of the HARP system. The emitting portion of the probe, shown in Fig ure 5, consists of $0.127 \mathrm{~mm}$ diameter tungsten wire bent to form a closed loop roughly $1.2 \mathrm{~mm}$ in diameter.

The filament is held inside two double bore pieces of $99.8 \%$ pure alumina epoxied to one larger double bore piece of $99.8 \%$ pure alumina. Two 18 AWG copper wire leads run the entire length of the $0.5 \mathrm{~m}$ probe up to the probe tip to reduce the resistance of the closed path and hence reduce the undesirable voltage drop associated with it. The ends of the tungsten filament are inserted down the small alumina tube along with additional lengths of $0.18 \mathrm{~mm}$ and 0.13 $\mathrm{mm}$ tungsten wire creating a snug fit. Additional tungsten wires (and the filament ends) are sandwiched in contact with the 18 AWG leads to ensure good contact between the tungsten and copper wires. The filament is further held in place by ceramic epoxy.

The "double tier" design of the emissive probe tip reduces the amount of blockage mass that is inserted into the discharge cathode plume. The probe is oriented such that the plane of the loop of the probe filament is perpendicular to the thruster axial direction. This allows the maximum axial resolution and bodes well with the axisymmetric nature of the discharge chamber and discharge cathode plume. Two identical probes were used during testing, due to breakage at the high HARP accelerations, each requiring a slightly different saturation heater current.

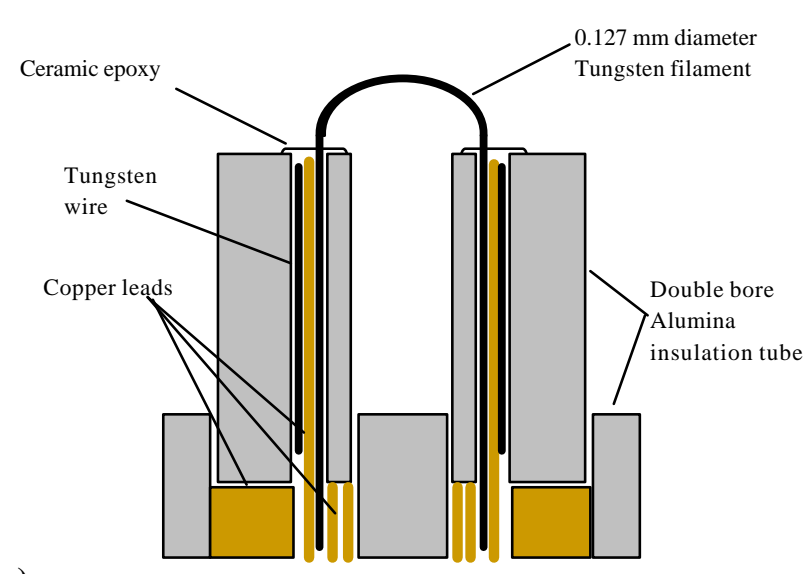

a)

Figure 5. Double tier emissive probe tip design internal schematic shown in a), and an external schematic of emissive probe tip design shown in b).

\section{Magnetic Field Effects}

The presence of large magnetic fields and large density gradients can lead to space-charge effects, causing disparity between the potential of the emitting probe and the actual local plasma potential. Space-charge effects can be avoided by sizing the probe such that the filament diameter, that is the diameter of the tungsten wire and not the loop diameter, is much less than the electron gyroradius. This condition has been shown by Hershkowitz to be equivalent to the following equation: ${ }^{18}$

$$
B<<\frac{4.8 \sqrt{T_{e V}}}{(d / 10)}
$$

In this equation, $\mathrm{T}_{\mathrm{eV}}$ is in $\mathrm{eV}, \mathrm{d}$ is the emitting filament diameter in $\mathrm{mm}$, and $\mathrm{B}$ is the magnetic field in Gauss. For this experiment the filament diameter is $0.127 \mathrm{~mm}$ and the electron temperature inside the discharge chamber ranges from $3-7 \mathrm{eV}$, based upon single and double Langmuir probe measurements made inside the discharge chamber of the FMT2 thruster. $^{20,21}$ Using the minimum electron temperature of $3 \mathrm{eV}$ and the emissive probe $0.127 \mathrm{~mm}$ filament diameter in the Hershkowitz equation, yields the restriction that $\mathrm{B}<<650 \mathrm{G}$. The magnetic field in the discharge chamber of the FMT2 has a maximum magnitude on the order of $100 \mathrm{G}$ at the exit plane of the discharge cathode and decreases with increasing axial and radial distances from the centerline DCA exit plane. The location of the highest magnetic field coincides with the position of the highest electron temperature. Thus, the Hershkowitz criterion is met even in the absolute worst scenario. 


\section{Emissive Probe Electronics}

The emissive probe circuit, illustrated in Figure 6, consists of the emissive probe, a dc power supply capable of supplying enough current to heat the filament, an isolation transformer to isolate the power supply from ground, and two isolation amplifiers to record both the emitting probe potential and the voltage drop across the filament. Data collection is built around two Analog Devices AD210 isolation amplifiers, which are capable of handling up to 2500 volts of common mode voltage and provide an input impedance of $10^{12} \Omega$. The low impedance output $(1 \Omega$ maximum) is connected to a Tektronix TDS 3034B digital oscilloscope which, when triggered off the probe position, records the plasma potential and filament voltage drop.

All plasma potential measurements are made with respect to the discharge cathode common and not the facility ground. Due to the recession of the probe tip inside the alumina tube when data collection is not taking place, floating potentials negative of discharge cathode common are observed. This expected result indicates the effectiveness of the magnetic field in confining the discharge plasma. The transverse diffusion of charged particles across the magnetic field lines is inhibited resulting in a floating potential somewhere between the bulk discharge plasma potential (in this case approximately $1100 \mathrm{~V}$ referenced to ground) and facility ground.

Typical floating potentials of the emissive probe in the "stored" configuration are $700 \mathrm{~V}$ with respect to ground (-

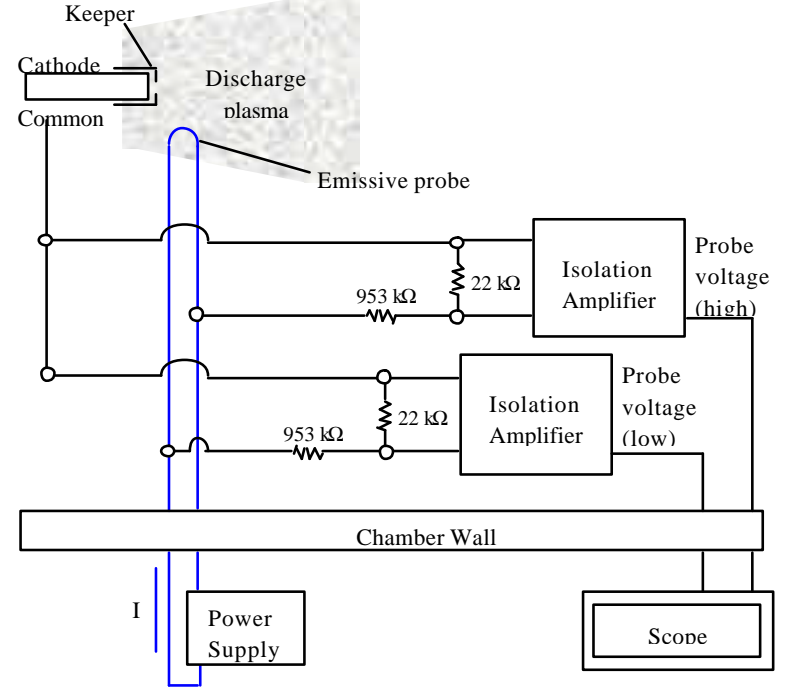

Figure 6. Emissive probe circuit. $400 \mathrm{~V}$ with respect to discharge cathode common). This relative voltage, combined with the restriction of the isolation amplifiers maximum allowable differential voltage, dictated the size of the voltage divider resistors and thus the resolution of the circuit. Both the "high" and "low" side floating potentials, of the power supply, are recorded indicating the uncertainty of the measurement, however, only the high side potentials are reported.

\section{Data Acquisition}

Adequate heater current must be applied to the filament to neutralize the probe sheath. The correct heater current is determined by taking several preliminary sweeps at the zero axial position and observing when the probe potential saturated. Figure 7 illustrates the difference between sufficient and insufficient heater current. With minimal heater current, the probe potential is well below cathode common potential. When the filament reaches the cathode plume there is a substantial jump in the probe potential. During the time that the probe is stationary in the discharge cathode plume, the probe floating potential increases as the plasma provides additional filament heating by the flux of high-energy particles in the high-density cathode plume.

At intermediate heater current, the probe potential continues to exhibit a sharp drop off in probe potential (a few hundred volts) immediately outside of the cathode plume. Increasing to sufficient heater current shifts the few hundred volt drop in probe potential to the location at which the probe is recessed inside the outer alumina tube. At this current, the probe potential is approximately at anode potential, outside of the outer alumina tube, and does not exhibit an increase in floating potential while the probe is stationary in the cathode plume. Once a sufficient heater current is determined, the emissive probe current is held at this value for the entire data collection domain. 


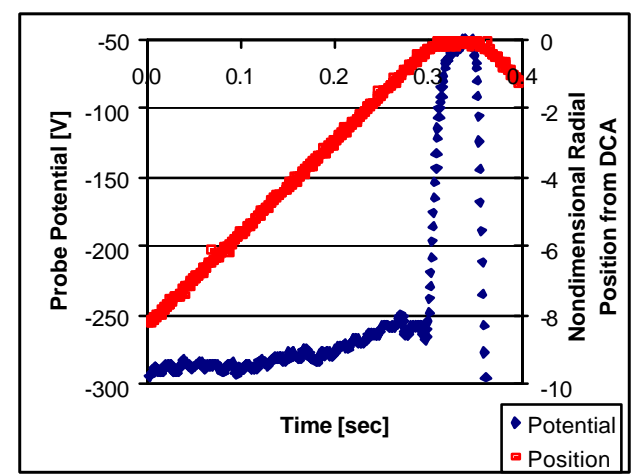

a)

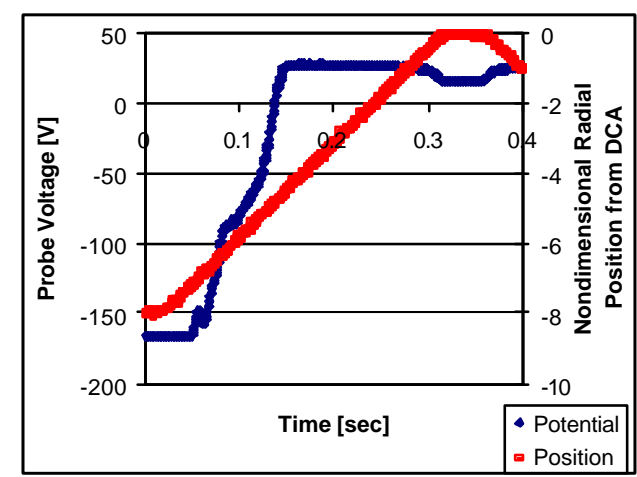

b)

Figure 7. Graphs of the emissive probe floating potential and position as a function of time made with respect to the discharge cathode common. The emissive probe tip exits the alumina tube into the discharge plasma after 0.15 seconds. The sweeps were taken at TOC 8a with a $V_{d c}=25.20$ volts and $J_{d c}=8.24$ A. Insufficient heater current (4.6 A) is indicated in a) with comparison to sufficient heater current $(5.0 \mathrm{~A})$ illustrated in b).

\section{Results and Discussion}

Figures $8-10$ illustrate the high side plasma potentials at various thruster operating conditions with beam extraction. An average value of the high and low side potential measurements would be shifted down approximately $1.5 \mathrm{~V}$. All potentials are in reference to the discharge cathode common of the FMT2 thruster. All discharge chamber positions have been normalized by the discharge cathode keeper diameter. The plasma potential contours demonstrate an on-axis minimum region indicating the plume structure of discharge cathode. Evaluation of the centerline plasma potential values does not support the existence of a potential hill structure at the operating conditions investigated. This does not completely rule out the potential hill as the contributor in discharge cathode assembly erosion since, under different cathode and thruster operating conditions, the potential hill structure may in fact exist and act as a mechanism to cause DCA erosion. The emissive probe measurement is repeatable for the two similar probes as well as slightly different engine operating conditions, evident by comparison of Figs. 8 and 9 , which were taken using different probes during different facility pump downs.

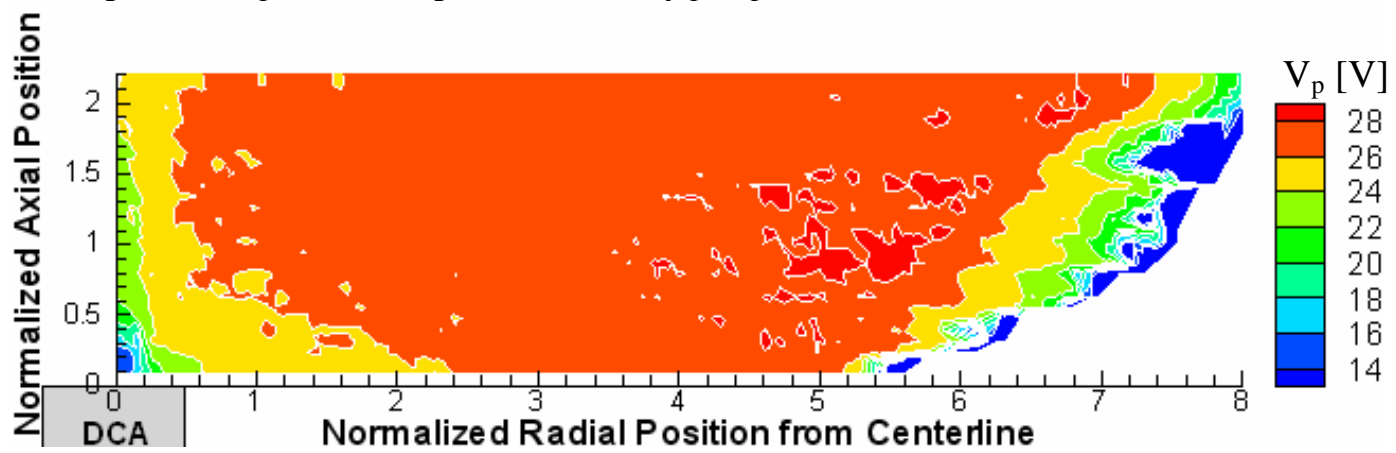

Figure 8. Plamsa potentials with respect to discharge cathode common for TOC 8a operating condition $\left(\mathrm{V}_{\mathrm{dc}}=\mathbf{2 5 . 2}\right.$ $V, J_{d c}=8.24 \mathrm{~A}$ ) taken with probe tip 1 with a heater current of $4.8 \mathrm{amps}$.

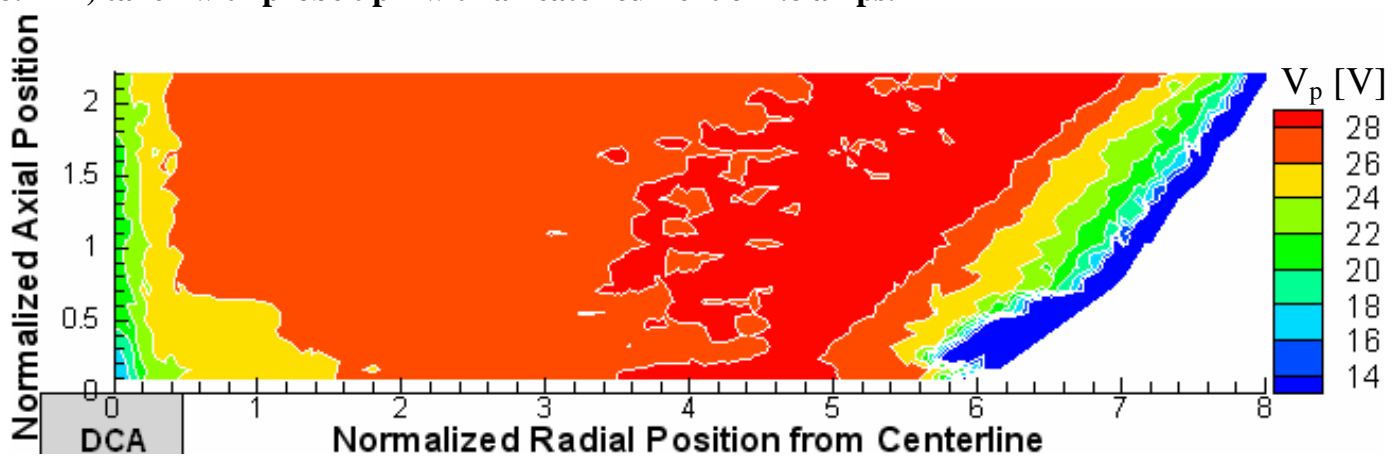


Figure 9. Plamsa potentials with respect to discharge cathode common for TOC 8 operating condition $\left(V_{d c}=25.2 \mathrm{~V}\right.$, $J_{d c}=8.24 \mathrm{~A}$ ) taken with probe tip 2 with a heater current of 5.0 amps.

Examination of the near DCA plasma structure shown in Fig. 10 illustrates very little variation as the engine is throttled up to higher power levels. Additionally, at the NASA TH 8 level, the discharge cathode keeper is intentionally shorted to the discharge cathode common to simulate the "shorting event" that occurred during the ELT at JPL. ${ }^{5,6}$ Shorting the cathode keeper does not change the near DCA plasma structure noticeably. Thus, shorting the keeper has no appreciable effect on the near-DCA plasma potential structure beyond the keeper sheath.

a)
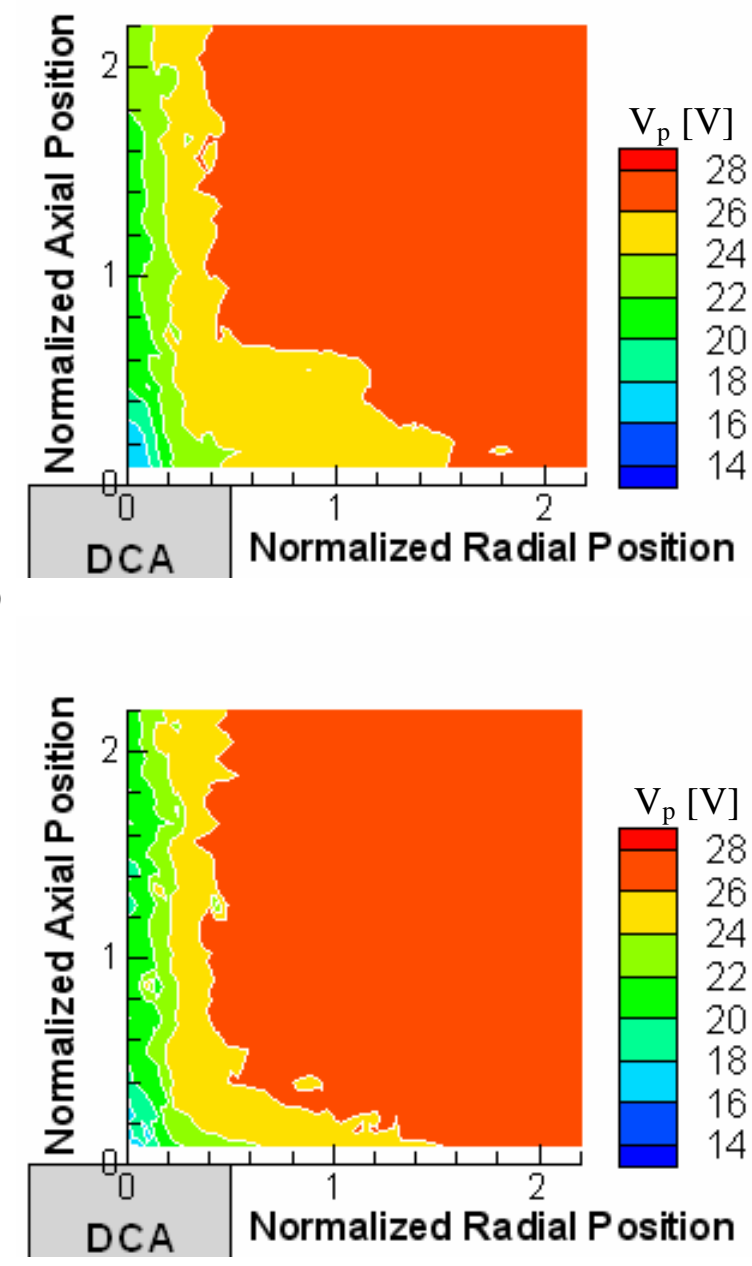

c)

Figure 10. Near DCA plasma potential measurements for the following thruster operating conditions: a) TOC 8 $\left(V_{\mathrm{dc}}=25.2 \mathrm{~V}, \mathrm{~J}_{\mathrm{dc}}=8.24 \mathrm{~A}\right)$, b) TOC 8 with cathode keeper shorted to cathode common $\left(\mathrm{V}_{\mathrm{dc}}=25.15 \mathrm{~V}, \mathrm{~J}_{\mathrm{dc}}=8.24 \mathrm{~A}\right)$, c) TOC $12\left(V_{d c}=25.40 \mathrm{~V}, J_{d c}=10.87 \mathrm{~A}\right)$, and TOC $15\left(V_{d c}=25.14 \mathrm{~V}, J_{d c}=13.13 \mathrm{~A}\right)$. All measurements were made with beam extraction, using probe tip 2 , a 5.0 A heater current, and are with respect to discharge cathode common.

Plasma potential measurements taken by a number of researchers indicate discharge plasma potentials at or a few volts above anode potential. ${ }^{9,22-25}$ Williams measured plasma potentials on a $6.4 \mathrm{~mm}$ diameter hollow cathode in a cylindrical anode with a xenon cathode flow rate of $4 \mathrm{sccm}$ and cathode emission current of 6 A. The measured plasma potentials were slightly above anode potential and decreased as the cathode was approached. ${ }^{9}$ The same trend is evident in Figures 8 - 10. Single Langmuir probe measurements in the FMT2 indicate a bulk dis charge plasma potential ranging from 27 to 30 volts away from the discharge cathode plume. ${ }^{21}$ The slight difference (a few volts) between the bulk discharge potentials is certainly within the error of the two measurements. 
Foster and Patterson have taken high-current hollow cathode measurements with a Langmuir probe near a 12.7 mm hollow cathode inside a ring-cusp magnetic field without beam extraction. A radial profile 3 mm downstream of the DCA exit plane, at a discharge current of $10.5 \mathrm{~A}$ and discharge voltage of $26.5 \mathrm{~V}$, shows a quick increase in plasma potential from $14 \mathrm{~V}$ at cathode centerline to $22 \mathrm{~V}$ near the keeper edge that was attributed to the existence of a double layer plasma structure formed between the discharge cathode plasma column and the main discharge. ${ }^{25}$ The relative magnitude of the near DCA and near anode potentials compared to the discharge voltage, as well as the well defined discharge cathode plume structure, coincide with those observed in this investigation.

Discharge cathode centerline data are readily compared again indicating little variation as the engine is throttled up in power. A slightly decreasing magnitude, less than 1 volt, is discernable as the engine is throttled up, but this trend is within the estimated error of the emissive probe measurement. Figure 11 illustrates this finding as well as the insensitivity of the DCA centerline potential data to shorting the discharge keeper to discharge cathode common at TOC 8 (roughly NASA TH 8).

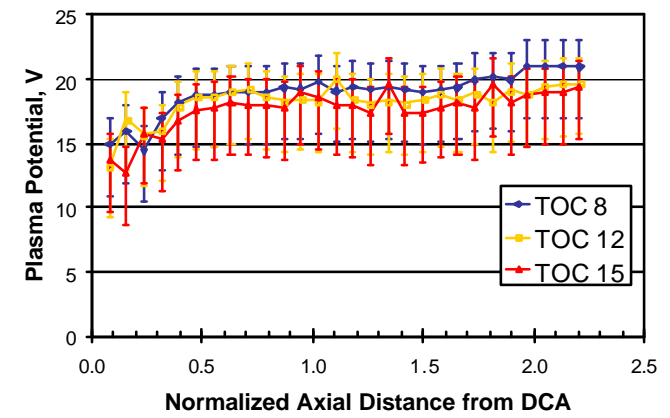

a)

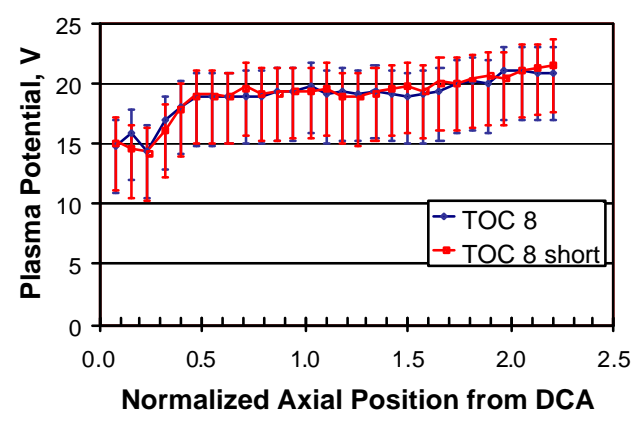

b)

Figure 11. Discharge cathode centerline plasma potential profiles for various throttling conditions are illustrated in a), while results from shorting the discharge keeper to cathode common is shown in b). All data are with beam extraction and show little variation.

\section{Error Analysis}

The floating power supply may not be perfectly isolated from ground, which introduces the possibility of leakage current when the probe and dc supply float at high potential. The result of appreciable leakage current is the probe floating at a value less than the true plasma potential. To determine the effect of the leakage current, the measured plasma potential near the anode is compared to the true anode potential. Figures $8-10$ illustrate that near the anode the measured plasma potential is at or a few volts above anode potential, which is consistent with measurements by other researchers. The combination of the aforementioned point and the higher than anode plasma potentials indicate that there is no appreciable leakage current.

Plasma potential measurement, with heater current through the filament, leads to a voltage drop across the filament. This voltage drop adds to the uncertainty in the measured value. The voltage drop is recorded during the test and is approximately $3 \mathrm{~V}$, leading to an uncertainty of \pm 1.5 volts. The effects of the leakage current and voltage drop contribute to an overall shift in absolute magnitude of plasma potential measurement leaving the relative potential measurements unaffected. An analysis by Hargus indicates that the apparent plasma potential of the probe filament is within several volts of the true plasma potential. ${ }^{26}$ Error bars in Figures 11 and 12 are indicated as $+2 /-4$ volts taking into account the high side selection of floating potentials.

Noise is reduced as much as possible by using coaxial cables for the entire circuit, both inside and outside of the chamber. Isolated feedthroughs permit a common grounding point for all circuit components, eliminating noise pick-up through ground loops.

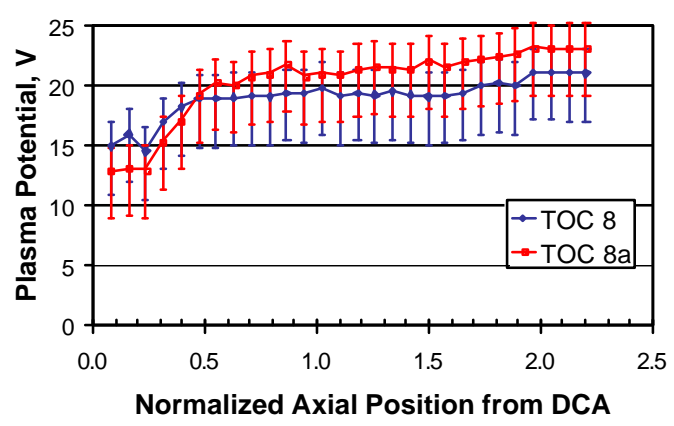

Figure 12. Centerline potential profiles for similar operating conditions using two tips and taken during separate pump downs. 
The perturbation of the discharge current by the probe insertion was recorded throughout the test. As expected the maximum perturbation occurred at the closest axial position on centerline. The temporary perturbation spike in discharge current is at most $10 \%$ of the nominal value. Outside of the discharge cathode plume region, no perturbation is detectable. Figure 12 supports the repeatability of the emissive probe measurement as the DCA centerline data taken with two different probes on different days of engine operation are comparable.

\section{Conclusions}

Plasma potential measurements inside the discharge chamber of a 30-cm ring-cusp ion thruster are presented for several operating conditions with beam extraction. The thruster operating conditions investigated corres pond to the operating conditions of the JPL Extended Life Test (ELT) in which anomalous discharge keeper erosion was observed. Plasma potential magnitudes are comparable to those measured by other researchers in electron bombardment discharge plasmas and are on the order of a few volts above anode potential away from the cathode plume. The discharge plasma contours are relatively insensitive to both the throttling of the engine and to shorting of the discharge cathode keeper to the discharge cathode common. The plasma potential contours illustrate a clearly defined region of lower potential where the discharge cathode plume resided indicative of a double layer. A minimum potential of approximately $14 \mathrm{~V}$ occurs on centerline at the closest axial position to the discharge cathode assembly. Plasma potential abruptly increases with increasing radial distance from the discharge cathode orifice, but increases more gradually in the axial direction. A potential hill structure is not observed, though the possibility for this structure to be present at other thruster operating conditions still exists. The potential increases to $26-28$ volts relative to cathode common near the anode. The anode is $\sim 25 \mathrm{~V}$ relative to cathode common during all tests.

\section{Acknowledgements}

We would like to thank the entire research group at PEPL who have been instrumental in this investigation. We would also like to thank Mr. Michael Patterson of the NASA Glenn Research Center (GRC) for the financial support of this research through research grant NAG3-2216 and for use of government equipment. We would like to acknowledge Dr. John Foster (grant monitor) and Dr. George Williams who have been principal contacts at NASA GRC. Mr. Daniel Herman is supported through a Department of Defense NDSEG fellowship.

\section{References}

[1] Polk, J. E., et al., "An Overview of the Results from an 8200 Hour Wear Test of the NSTAR Ion Thruster," AIAA Paper \# 99-2446, 35 ${ }^{\text {th }}$ AIAA / ASME / SAE / ASEE Joint Propulsion Conference, Los Angeles, CA, June 1999.

[2] Williams, G. J., et al., "Characterization of FMT-2 Discharge Cathode Plume," IEPC Paper \#99-104, 26 ${ }^{\text {th }}$ International Electric Propulsion Conference, Ketakiushu, Japan, Oct. 1999.

[3] Anderson, J. R., et al, "Performance Characteristics of the NSTAR Ion Thruster During and On-Going Long Duration Ground Test,” IEEE Paper No. 8.0303, IEEE Aerospace Conference, Big Sky, MT, Mar. 2000.

[4] Domonkos, M. T., Foster, J. E., Patterson, M. J., "Investigation of Keeper Erosion in the NSTAR Ion Thruster," IEPC Paper No. 01-308, $27^{\text {th }}$ International Electric Propulsion Conference, Pasadena, CA, Oct. 2001.

[5] Sengupta, A., Brophy, J. R., and Goodfellow, K. D., "Wear Characteristic from the Extended Life Test of the DS1 Flight Spare Ion Thruster," $28^{\text {th }}$ International Electric Propulsion Conference, Toulouse, France, March 17-21, 2003.

[6] Sengupta, A., Brophy, J. R., and Goodfellow, K. D., "Status of the Extended Life Test of the Deep Space 1 Flight Spare Ion Engine after 30,352 Hours of Operation," AIAA-2003-4558, 39 $9^{\text {th }}$ AIAA / ASME / SAE / ASEE Joint Propulsion Conference, Huntsville, AL, June 20-23, 2003.

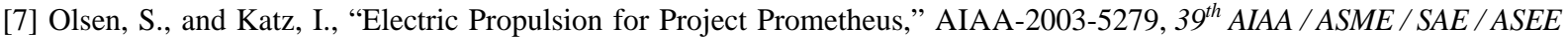
Joint Propulsion Conference, Huntsville, AL, June 20-23, 2003.

[8] Patterson, M.J., Foster, J.E., Haag, T.W., Pinero, L., Soulas, G.C., "Ion Propulsion Development Activities at the NASA Glenn Research Center," AIAA-2003-4709, 39 ${ }^{\text {th }}$ AIAA / ASME / SAE / ASEE Joint Propulsion Conference, Huntsville, AL, June 20-23, 2003.

[9] Williams, G. J., The Use of Laser-Induced Fluorescence to Characterize Discharge Cathode Erosion in a $30 \mathrm{~cm}$ RingCusp Ion Thruster, Ph.D. Dissertation, University of MI, 2000.

[10] Kameyama, I., and P. J. Wilbur, "Potential-Hill Model of High-Energy Ion Production Near High-Current Hollow Cathodes," ISTS-98-Aa2-17, 21 ${ }^{\text {st }}$ International Symposium on Space Technology and Science, (May, 1998).

[11] Hayakawa, et al, "Measurements of Electron Energy Distributions in a $14 \mathrm{~cm}$ Diameter Ring Cusp Ion Thruster," Journal of Propulsion and Power, Vol. 8, pp. 118-126, Jan-Feb, 1992.

[12] Herman, D. A., McFarlane, D. S., and Gallimore, A. D., "Discharge Plasma Parameters of a 30-cm Ion Thruster Measured without Beam Extraction using a High-Speed Probe Positioning System," IEPC-03-0069, $28^{\text {th }}$ International Electric Propulsion Conference, Toulouse, France, March 17-21, 2003. 
[13] Walker, M. L. R., Gallimore, A. D., "Pressure Map of a Facility as a Function of Flow Rate to Study Facility Effects," AIAA-2002-3815, 38 $8^{\text {th }}$ Joint Propulsion Conference, Indianapolis, Indiana, July 7-10, 2002.

[14] Hofer, R. R., Peterson, P. Y., Gallimore, A. D., "Characterizing Vacuum Facility Backpressure Effects on the Performance of a Hall Thruster," IEPC Paper No. 01-045, $27^{\text {th }}$ International Electric Propulsion Conference, Pasadena, CA, Oct. 2001.

[15] Dushman, S., Scientific Foundations of Vacuum Technique, Vol. 4, Wiley, N.Y., 1958.

[16] Haas, J. W., et al, "Development of a High-Speed, Reciprocating Electrostatic Probe System for Hall Thruster Interrogation,” Review of Scientific Instruments. Vol. 71, No. 11, pp. 4131-4138, Nov. 2000.

[17] Haas, J. W., Low-Perturbation Interrogation of the Internal and Near-Field Plasma Structure of a Hall Thruster using a High-Speed Probe Positioning System, Ph.D. Dissertation, University of Michigan, 2001.

[18] Hershkowitz, N., and Cho, M., "Measurement of Plasma Potential by Electron Emissive Probes," Journal of Vacuum Science and Technology A, Vol. 6, No. 3, May 1988, pp. 2054.

[19] Kemp, R., and Sellen, J., "Plasma Potential Measurements by Electron Emissive Probes," Review of Scientific Instruments, Vol. 37, No. 4, April 1966, pp. 455.

[20] Herman, D.A., and Gallimore, A.D., "Comparison of Discharge Plasma Parameters in a 30-cm NSTAR Type Ion Engine with and without Beam Extraction," AIAA-2003-5162, 39 th AIAA / ASME / SAE / ASEE Joint Propulsion Conference, Huntsville, AL, June 20-23, 2003.

[21] Herman, D.A., and Gallimore, A.D., "Discharge Chamber Plasma Structure of a $30 \mathrm{~cm}$ NSTAR-type Ion Engine," AIAA-2004-3794, 40 ${ }^{\text {th }}$ AIAA / ASME / SAE / ASEE Joint Propulsion Conference, Fort Lauderdale, FL, 11 - 14 July, 2004.

[22] Beattie, J. R., and Matossian, J. N., Mercury Ion Thruster Technology Final Report, NASA CR-174974, Hughes Research Labs. Feb. 1983 - Oct. 1984.

[23] Friedly, V.J., and Wilbur, P.J., "High Current Hollow Cathode Phenomena," AIAA-90-2587, $21^{\text {st }}$ AIAA / DGLR / JSASS International Electric Propulsion Conference, Orlando, FL, July 18-20, 1990.

[24] Wilbur, P.J., and Isaacson, J., Plasma Property Contours in a $15 \mathrm{~cm}$ Hollow Cathode Kaufman Thruster, NASA CER72-73-PJW20, Colorado State University, Feb. 1973.

[25] Foster, J. E., and Patterson, M. J., "Plasma Emission Characteristics from a High Current Hollow Cathode in an Ion Thruster Discharge Chamber," AIAA-2002-4102, 38 th AIAA / ASME / SAE / ASEE Joint Propulsion Conference, Indianapolis, Indiana, July 7-10, 2002.

[26] Hargus, W. A., and Cappelli, M. A., 'Interior and Exterior Laser-Induced Fluorescence and Plasma Potential Measurements on a Laboratory Hall Thruster," AIAA-1999-314272, 35 ${ }^{\text {th }}$ AIAA / ASME / SAE / ASEE Joint Propulsion Conference, Los Angeles, California, June 20-24, 1999. 